\title{
Chloroorganic Pesticide Adsorption from Water Solution Using Sewage Sludge Vermicompost as a Natural Sorbent
}

\author{
Katarzyna Ignatowicz' \\ 1 Department of Technology in Engineering and Environmental Protection, Białystok University of Technology, \\ ul.Wiejska 45a, 15-351 Białystok, Poland, e-mail: k.ignatowicz@pb.edu.pl
}

\begin{abstract}
Dozens of thousands of tons of pesticide waste have been stored since 1950s. The corrosion of concrete bunkers and wells where the expired pesticides are deposited causes the risk of toxic leakage due to deteriorating conditions of these constructions. Such hazardous spill might be transported by underground waters in the form of so-called underground inflow and subsequently might reach a network of surface waters. Evaluating the adsorption potential of natural sorbent for pesticide was the main goal of this research. The adsorption balance was examined in order to analyze the influence of the adsorption mechanism of $\mathrm{HCH}$ molecules on vermicompost. The adsorption of $\mathrm{HCH}$ isotherms by vermicompost at constant temperature was tested experimentally. The Freundlich, Langmuir and BET's adsorption isotherm models describe the experimental data within the acceptable error ranges. The Freundlich model proved to be more suitable for the experimental data. The form of isotherms indicates that $\mathrm{HCH}$ is adsorbed as a monolayer; therefore no obstacles occur in order for water and pesticide molecules to cover the adsorption surface.
\end{abstract}

Keywords: sorption, vermicompost, isotherm, pesticide

\section{INTRODUCTION}

Pesticides are toxic chemicals used to eradicate numerous pests and diseases. These compounds might be carcinogenic, teratogenic, embryotoxic, and mutagenic. Improperly stored, unused or expired pesticides become dangerous waste, which infiltrates into the natural environment in an uncontrolled way, thus posing a threat to all living organisms. Dozens of thousands of tons of pesticide waste have been stored since 1950s (Ignatowicz, 2011, 2017). The corrosion of concrete bunkers and wells where the expired pesticides are deposited causes the risk of toxic leakage due to deteriorating conditions of these constructions (Ignatowicz, 2011). Such hazardous spill might be transported by underground waters in the form of so-called underground inflow and subsequently might reach a network of surface waters (Ignatowicz, 2017). Evaluating the adsorption potential of natural sorbent for pesticide was the main goal of this research. The adsorption balance was examined in order to analyze the influence of the adsorption mechanism of $\mathrm{HCH}$ molecules on vermicompost.

\section{SORPTION ISOTHERMS}

Among the several existing isotherms, the sorption data were subjected to five commonly used isotherms models, namely (Table 1) Langmuir (1918), Freundlich (1894), BET (1938), to evaluate the maximum saturation capacity of adsorbent (Ochsner et al., 2006; Atkins, 2006).

The first mathematical fit to an isotherm was published by Freundlich and is a purely empirical formula for microporous and heterogeneous adsorbates:

$$
\mathrm{q}_{\mathrm{e}}=\mathrm{K}_{\mathrm{F}} \mathrm{C}^{1 / \mathrm{n}}
$$

where: $q_{e}(\mathrm{mg} / \mathrm{g})$ is the amount of $\mathrm{HCH}$ adsorbed on the adsorbent surface at equilibrium, $c(\mathrm{mg} / \mathrm{L})$ the $\mathrm{HCH}$ concentration in aqueous solutions at equilibrium, 
$K_{F}-$ constant - is the maximum multilayer adsorption capacity and

$1 / n$ is a characteristic constant which measures the adsorption intensity $\left(K_{F}\right.$ and $\mathrm{n}$ are empirical constants for each adsorbent-adsorbate pair at a given temperature).

As the temperature increases, the constants $\mathrm{k}$ and $\mathrm{n}$ change to reflect the empirical observation that the quantity adsorbed rises more slowly and higher pressures are required to saturate the surface.

Langmuir isotherm is a semi-empirical isotherm derived from the proposed kinetic mechanism. Langmuir isotherm constitutes a model for monolayer localized physical adsorption on a homogeneous surface; it may be extended with heterogeneity effects, lateral interactions and multilayer effects. It is based on four assumptions:

- The surface of the adsorbent is uniform, that is, all the adsorption sites are equivalent,

- Adsorbed molecules do not interact,

- All adsorption occurs through the same mechanism,

- At the maximum adsorption, only a monolayer is formed: molecules of adsorbate do not deposit on other, already adsorbed, molecules of adsorbate, only on the free surface of the adsorbent.

The Langmuir equation may be written as:

$$
\mathrm{q}_{\mathrm{e}}=\mathrm{q}_{\mathrm{m}} \frac{k c}{1+k c}
$$

where: $q_{e}(\mathrm{mg} / \mathrm{g})$ is the amount of $\mathrm{HCH}$ adsorbed on the adsorbent surface at equilibrium, $c(\mathrm{mg} / \mathrm{L})$ the $\mathrm{HCH}$ concentration in aqueous solutions at equilibrium,

$q_{m}(\mathrm{mg} / \mathrm{g})$ is the maximum monolayer adsorption capacity, $\mathrm{k}$ is the constant related to the free energy of adsorption.

Molecules often form multilayer, that is, some are adsorbed on already adsorbed molecules and the Langmuir isotherm is not valid. In 1938, Stephan Brunauer, Paul Emmett, and Edward Teller developed a model isotherm that takes that possibility into account. The Langmuir isotherm is usually better for chemisorption and the BET isotherm works better for physisorption for nonmicroporous surfaces. The BET equation may be written as:

$$
\Theta=\frac{1}{1-c}\left(\frac{K c}{1+(k-1) c}\right)
$$

where: $\Theta\left(\mathrm{q}_{\mathrm{e}} / \mathrm{q}_{\mathrm{m}}\right)$ is the fractional coverage, $c(\mathrm{mg} / \mathrm{L})$ the $\mathrm{HCH}$ concentration in aqueous solutions at equilibrium,

$k$ is the constant related to the free energy of adsorption.

\section{METHODS}

\section{Sorbate}

On the basis of the literature data and own studies, chloroorganic pesticides that most often occurred in the drinking water near the graveyards

\begin{tabular}{|c|c|c|c|c|c|}
\hline Isotherm & $\begin{array}{c}\text { Type of relation of } \\
\text { physicochemical quantities }\end{array}$ & Formula & Linear formula & $\begin{array}{l}\text { Formula } \\
\text { constant }\end{array}$ & $\begin{array}{l}\text { Method of } \\
\text { estimation }\end{array}$ \\
\hline \multicolumn{6}{|c|}{ Monolayer } \\
\hline Freundlich & $\begin{array}{l}\text { Adsorption on } \\
\text { heterogeneous surface } \\
\text { with monolayer effect; } \\
\text { micro-porous solids }\end{array}$ & $q_{e}=K_{F} C_{e}{ }^{1 / n}$ & $\begin{array}{l}\ln \mathrm{q}_{\mathrm{e}}=\ln \mathrm{K}_{\mathrm{F}}+\frac{1}{n} \ln \\
\mathrm{C}_{\mathrm{e}}\end{array}$ & $\begin{array}{l}A=k c^{1 / n} \\
n, k\end{array}$ & $\begin{array}{l}\text { Gauss- } \\
\text { Newton }\end{array}$ \\
\hline Langmuir & $\begin{array}{l}\text { Adsorption on } \\
\text { homogeneous surface with } \\
\text { monolayer effect (lateral } \\
\text { inter-actions and multilayer } \\
\text { effect may be easily } \\
\text { incorporated) }\end{array}$ & $\mathrm{q}_{\mathrm{e}}=\frac{q b c}{1+b c}$ & $\mathrm{q}_{\mathrm{e}}=\frac{1}{b} \frac{q}{c}+\mathrm{q}$ & $\begin{array}{l}A=a c / 1+k c \\
a, k\end{array}$ & $\begin{array}{l}\text { Gauss- } \\
\text { Newton }\end{array}$ \\
\hline \multicolumn{6}{|c|}{ Multilayer } \\
\hline BET & $\begin{array}{l}\text { Adsorption on } \\
\text { homogeneous surface with } \\
\text { multilayer effect }\end{array}$ & $\Theta=\frac{1}{1-c}\left(\frac{K c}{1+(k-1) c}\right)$ & $\begin{array}{l}\frac{c}{q e(1-c)}=\frac{1}{q m k}+ \\
\frac{k-1}{q m k} c\end{array}$ & $\begin{array}{l}A=a c /(1+c)(1+k c) \\
a, k\end{array}$ & $\begin{array}{l}\text { Gauss- } \\
\text { Newton }\end{array}$ \\
\hline
\end{tabular}

Table 1.The sorption isotherms 
at the highest concentrations were selected as representative sorbate (Ignatowicz, 2009; 2011). Individual pure active substances $\mathrm{HCH}$ were applied. Technical grade $\mathrm{HCH}$ of $99.8 \pm 0.2 \%$ purity obtained from Institute of Industrial Organic Chemistry Analytical Department in Poland was used as a sorbate. A sample solution of pesticide has been prepared by dissolving $1 \mathrm{~g}$ of pesticide in $10 \mathrm{ml}$ of methanol and then diluted to $1 \mathrm{~L}$ with twice distilled deionised water. The prepared solutions were applied in the concentrations of $10 \mathrm{mg}$ pesticide per litre.

\section{Sorbent}

The vermicompost made from municipal sewage sludge after aerobic stabilization was applied as a sorbent. The characteristics of the compost are given in Table 2 . The used waste products comply with the requirements of the Regulation of the Minister of the Environment concerning agricultural usage of municipal sewage sludge.

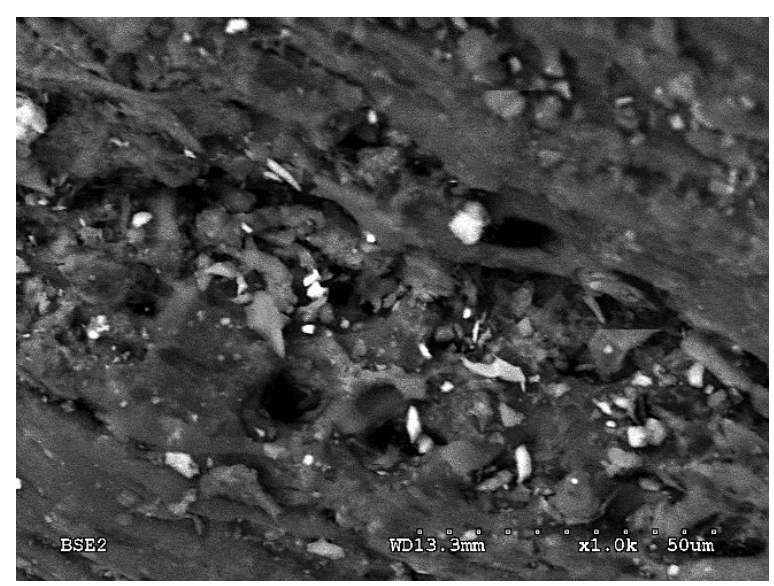

Figure 1. Scanning electron microscope (SEM) photos of vermicompost.

Table 2. The characteristics of vermicompost

\begin{tabular}{|l|l|l|l|l|l|l|}
\hline \multicolumn{7}{|c|}{ Manurial $\left(\mathrm{mg} / \mathrm{kg}_{\mathrm{dm}}\right)$} \\
\hline $\mathrm{Ca}$ & $\mathrm{Mg}$ & $\mathrm{Nog}$ & $\mathrm{N}_{\mathrm{NH}}{ }_{4}^{+}$ & $\mathrm{Pog}$ & $\mathrm{C}$ & $\mathrm{K}$ \\
\hline 20.2 & 4.2 & 8.1 & 0.2 & 6.1 & 265.8 & 2.2 \\
\hline \multicolumn{7}{|c|}{ Metal $\left(\mathrm{mg} / \mathrm{kg}_{\mathrm{dm}}\right)$} \\
\hline $\mathrm{Pb}$ & $\mathrm{Cu}$ & $\mathrm{Cd}$ & $\mathrm{Cr}$ & $\mathrm{Ni}$ & $\mathrm{Zn}$ & $\mathrm{Hg}$ \\
\hline 53.4 & 67.1 & 8.3 & 316.3 & 8.5 & 1231 & 1.2 \\
\hline \multicolumn{7}{|c|}{ Permissible standard } \\
\hline 500 & 800 & 10 & 500 & 100 & 2500 & 5 \\
\hline \multicolumn{7}{|c|}{ Other (\%) } \\
\hline $\mathrm{pH}$ & Hydration & Dry mass & Organic matter \\
\hline 5.88 & 46.0 & 54.0 & 54.0 \\
\hline
\end{tabular}

\section{Sorption procedure}

The studies were performed under static conditions in accordance with the methodology applied in Belgium, Germany, France, Italy, England, the USA, Poland and other countries (Ignatowicz, 2011, 2017; Hamadi et al., 2004; Hamdaoui et al., 2007; Kumar et al., 2003; Witbowo et al., 2007; Yuh-Shan, 2006; Sahaa et al., 2008; El-Sharkawy et al., 2006).

Sorbent after prior degassing, cleansing with distilled water and drying, was crushed with a mortar and dried using an electric drier at the temperature of $150^{\circ} \mathrm{C}$ for 3 hours until it became solid mass. From such material test portions were prepared with the mass of $0.001-0.025 \mathrm{~g}$ for $100 \mathrm{ml}$ of solution. Representative sorbent samples were added to the conical flasks containing pesticide solution with the concentration of $10 \mathrm{mg} / \mathrm{L}$.

The flasks were shaken on a vortex mixer with constant vibration amplitude for 24 hours, then they were left for 24 hours in order to obtain full sorption balance. After that time, the samples underwent double filtration using soft tissue drains. The first and last portions of the filtrate were discarded. Then, the pollutant concentration in the filtrate was measured, according to the accepted method. The sorption process analysis was conducted on the basis of the obtained results (using Statistica software). The Freundlich, Langmuir, BET, Temkin and Jovanovic isotherms were estimated as non-linear models with the least squares method with the use of Gauss-Newton algorithm.

\section{Analytical procedure}

The $\mathrm{HCH}$ concentrations were determined in the collected samples in accordance with the obligatory methodology using an AGILENT6890 gas chromatograph equipped with ECD and NPD detector. The injector temperature was $210^{\circ} \mathrm{C}$ and the flow rate of helium was $1.0 \mathrm{~mL} / \mathrm{min}$. The column DB $(35 \mathrm{~m}$ length - $0.32 \mathrm{~mm}$ i.d. $0.5 \mu \mathrm{m}$ film thickness) temperature was set at $120^{\circ} \mathrm{C}$ for $2 \mathrm{~min}$ and increased at a rate of $13{ }^{\circ} \mathrm{C} / \mathrm{min}$ to $190^{\circ} \mathrm{C}$. The temperature was finally increased to $295^{\circ} \mathrm{C}$ and maintained isothermally for $20 \mathrm{~min}$ (Balinova, 1996; Głowacki, 2014; Hussen et al., 2007; Kogut et al., 2014). 


\section{RESULTS AND DISCUSSION}

The achieved study results are presented in Figure 3. The characteristics of the applied adsorbent (Table 1) indicate that the requirements of compost for natural applications are met. The parameters calculated according to the isotherm models under study are listed in Table 3 . The adsorption process is described using Freundlich's, Langmuir's, Tiemkin, Jovanovic and BET's formulae:

$$
\begin{aligned}
& \text { Freundlich } \mathrm{A}=\mathrm{kc}^{1 / \mathrm{n}} \\
& \text { Langmuir } \mathrm{A}=\mathrm{a}_{\mathrm{m}} \mathrm{kc} / 1+\mathrm{kc} \\
& \text { BET } \mathrm{A}=\mathrm{ac} /(1+\mathrm{c})(1+\mathrm{kc})
\end{aligned}
$$

The following curves were achieved $A_{F}=422.3 \mathrm{c}^{0.35}$ for compost at coefficient of correlation of $\mathrm{R}=0.91 ; \mathrm{A}_{\mathrm{L}}=3175.6 \mathrm{c} / 1-1077.4 \mathrm{c}$ at the coefficient of correlation equal $\mathrm{R}=0.75$; and $\mathrm{A}_{\mathrm{BET}}=5321.2 \mathrm{c} /(1+\mathrm{c})(1-4.89 \mathrm{c})$ at the coefficient of correlation $\mathrm{R}=0.76$.

The isotherms were calculated applying the Statistica software by means of the least squares by Gauss-Newton method; the achieved constants $\mathrm{a}$ and $\mathrm{k}$ are presented in Figure 3. The figure presents the adsorption isotherms for the studied $\mathrm{HCH}$ pesticide on vermicompost as a function of adsorbate amount adsorbed by adsorbent weight unit $(\mathrm{x} / \mathrm{m})$ vs. concentration of the $\mathrm{HCH}$ at the equilibrium ( $\mathrm{c} 0)$.

The correlation coefficients (R) were employed to ascertain the fit of all isotherms with the experimental data. From Table 3, the values of $\mathrm{R}$ coefficients were found higher for the Freundlich model than for the Langmuir and BET models. This indicates that the Freundlich isotherms are clearly the best fitting isotherm model for the experimental data. (Neethu et al., 2017; Ignatowicz, 2017).

The nature of the studied $\mathrm{HCH}$ pesticide (a chlorinated and hydrophobic molecule) suggests that its adsorption is of the hydrophobic type directly bound to the specific surface of the adsorbent particles (Hamadi et al., 2004). The isotherms study was performed according to the protocol described in the experimental chapter. The obtained results lead, firstly, to plot a, the amount of $\mathrm{HCH}$ adsorbed on the vermicompost surface at equilibrium $(\mathrm{mg} / \mathrm{g})$ against $\mathrm{c}_{\mathrm{e}}$, the $\mathrm{HCH}$ concentration in the aqueous solution at equilibrium in order to classify the isotherms according to
Table 3. The coefficients of the adsorption isotherms (level of confidence $95 \%, \alpha=0.05$ )

\begin{tabular}{|c|c|c|c|}
\hline Izoterm & $\mathrm{a}$ & $\mathrm{b}$ & $\mathrm{R}$ \\
\hline Freundlich & 422.3 & 0.35 & 0.91 \\
\hline Langmuir & 3175.6 & -1077.4 & 0.75 \\
\hline BET & 5321.2 & -4.89 & 0.76 \\
\hline
\end{tabular}

the classification of Giles et al., 1960 (Hamdaoui et al., 2007). This one includes four main groups: $\mathrm{L}, \mathrm{H}, \mathrm{S}$ and $\mathrm{C}$. The experimental adsorption isotherms of $\mathrm{HCH}$ in aqueous solutions on the studied carbon are presented in Figure 3. The isotherm according to Giles' classification (L) was achieved for HCH. (Neethu et al., 2017; Moawed et al., 2017; Chin-Pampillo, 2016) The L shape of the adsorption isotherms means that there is no strong competition between the solvent and the adsorbate to occupy the adsorbent surface sites. In this case, the longitudinal axes of the adsorbed molecules are parallel to the adsorbent surface (molecules adsorbed flat on the surface). Figure 3 shows that the value of experimental maximum adsorption capacity (qm experimental) for the chloroorganic compound $\mathrm{HCH}$ on vermicompost is about $225 \mathrm{mg} / \mathrm{g}$.

According to Hamdaoui and Nafrechoux, the $\mathrm{HCH}$ molecules bind to the adsorbent only through one grouping and the adsorption becomes progressively easier as the absorbed quantity increases. Thus, the first fixed molecules facilitate the adsorption of the following molecules because of the lateral attraction. The shape of these isotherms indicates that the $\mathrm{HCH}$ is adsorbed as a monolayer and that there is no strong competition between the pesticide molecules and water to occupy the adsorption surface sites. In this case,

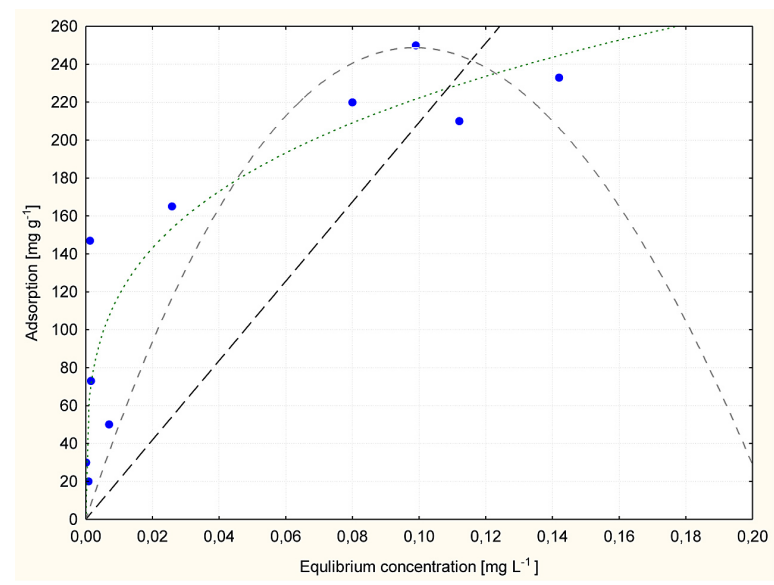

Figure 2. The comparison of model's isotherms of pesticide on compost 
the longitudinal axes of the adsorbed molecules are parallel to the adsorbent surface. This type of isotherm is relative to microporous adsorbents with a diameter lower than $25 \AA$, the adsorbent being saturated at the moment of the monolayer replenishment (Ignatowicz, 2011, 2017; Hamdaoui, 2007). Therefore, there would be weak interactions on these adsorbent surfaces because the number of layers cannot increase freely.

The equilibrium data were further analyzed using the Freundlich equation using the same set experimental data, by plotting $\ln$ qe versus Ce. The calculated Freundlich isotherm constants and the corresponding coefficient of correlation values were shown in Table 3 . The coefficients of correlation are high $(\mathrm{R} \geq 0.921)$ showing a good linearity. The magnitude of the exponent $n$ $(\mathrm{n}=1.36)$ gives an indication on the favorability of adsorption. It is generally stated that values of $\mathrm{n}$ in the range 2-10 represent good, 1-2 moderately difficult, and less than 1 poor adsorption characteristics.

The knowledge on the $1 / \mathrm{n}$ parameter value in Freundlich's formula allows for assessing the adsorption intensity of a given substance from water phase on adsorbent; value of KF constant determines the sorption capacity of an adsorbent at balance concentration in a solution. Higher KF value corresponds to higher sorption capacity. In the author's own studies, higher value of KF coefficient was achieved for vermicompost, which proves its usefulness in application as sorption $\mathrm{HCH}$. Constants $1 / \mathrm{n}$ in Freundlich's formula constitute directional coefficients of isotherms equal to the tangent of line inclination angle in logarithmic coordinates. Therefore, the higher the $1 / n$ value, the more intensive the adsorption process.

\section{CONCLUSIONS}

The present study indicates the suitability of the vermicompost for removal of graveyard chloroorganic pesticide $\mathrm{HCH}$ from aqueous solutions. The adsorption process is described using Freundlich, Langmuir, and BET formulae. The Freundlich model was better as far as fitting the experimental data is concerned.

The group of isotherms according to Giles' classification (L) was achieved for chloroorganic pesticide. The $\mathrm{HCH}$ molecules bind to the adsorbent through only one grouping and the adsorption becomes progressively easier as the absorbed quantity increases. Thus, the first fixed molecules facilitate the adsorption of the following molecules because of the lateral attraction. The shape of these isotherms indicates that the chloroorganic pesticide $\mathrm{HCH}$ is adsorbed as a monolayer and that there is no strong competition between the pesticide molecules and water to occupy the adsorption surface sites. In this case, the longitudinal axes of the adsorbed molecules are parallel to the adsorbent surface. This type of isotherm is relative to microporous adsorbents with a diameter lower than $25 \AA$, the adsorbent being saturated at the moment of the monolayer replenishment.

\section{Acknowledgements}

The study was conducted as a research project S/WBiIŚ/3/2014 in Faculty of Building and Environmental Engineering of BUT in the Department of Technology in Engineering and Environmental Protection and financed by Ministry of Science and Higher Education.

\section{REFERENCES}

1. Atkins P.W., 2006. Physical chemistry, 8th ed., Oxford University Press

2. Balinova A. 1996. Strategies for chromatographic analysis of pesticide residues in water. J. Chromatogr. A 754, 125-135.

3. Chin-Pampillo J.S., Masís-Mora M., Ruiz-Hidalgo K., Carazo-Rojas E., Rodríguez C.E., 2016, Removal of carbofuran is not affected by co-application of chlorpyrifos in a coconut fiber/compost based biomixture after aging or pre-exposure. J Environ. Sci., 46, 182-189.

4. El-Sharkawy I.I., Saha B.B., Koyama S., Choon $\mathrm{Ng} \mathrm{K}$., 2006, A study on the kinetics of ethanolactivated carbon fiber: Theory and experiments, Int. J Heat and Mass Tran. 49, 3104-3110.

5. Głowacki M., Ciesielczuk T., 2014, Assessment of pahs and selected pesticides in shallow groundwater in the highest protected areas in the Opole region, Poland. J. Ecol. Eng.15(2), 17-24.

6. Hamadi N.K., Swaminathan S., Chen X.D., 2004, Modeling of adsorption isotherms of phenol and chlorophenols onto granular activated carbon Part I. Two-par ameter models and equations allowing determination of thermodynamic parameters. J. Hazard. Mater. B112, 133-141.

7. Hamdaoui O., Naffrechoux E., 2007 Modeling of adsorption isotherms of phenol and chlorophenols onto granular activated carbon - Part I. Two-pa- 
rameter models and equations allowing determination of thermodynamic parameters. J. Hazard. Mater. 147, 381-394.

8. Hussen A., Westbom R., Megersa N., Mathiasson L., Bjorklund E. 2007. J Chromatogr. A 1152, 247-251.

9. Ignatowicz K. 2017. The impact of sewage sludge treatment on the content of selected heavy metals and their fractions. Environ. Res. 156, 19-22.

10. Ignatowicz K., 2011, Metals content chosen for environmental component monitoring in graveyards, Fresen. Environ. Bull. 20 (1a), 270-273.

11. Kogut P., Piekarski J., Ignatowicz K., 2014 Start-up of Biogas Plant with Inoculating Sludge Application, Rocznik Ochrona Środowiska, 16, 534-545.

12. Kumar A., Kumar S., Kumar S. 2003. Adsorption of resorcinol and catechol on granular activated carbon: Equilibrium and kinetics. Carbon 41, 3015-3025.

13. Moawed E.A.,. Radwan A.M, 2017, Application of acid modified polyurethane foam surface for detection and removing of organochlorine pesticides from wastewater. Journal of Chromatogr. B, 15,
1044-1045.

14. Neethu Narayanan, Suman Gupta, Gajbhiye V.T., Manjaiah K.M., 2017. Optimization of isotherm models for pesticide sorption on biopolymer-nanoclay composite by error analysis, Chemosphere, 173, 502-511.

15. Ochsner T.E., Stephens B.M., Koskinen W.C., Kookana R.S., 2006 Sorption of a hydrophilic pesticide. Soil Sci. Soc. Am. 70, 1991-1997.

16. Sahaa B.B., Chakraborty A., Koyama S., Yoon S., Mochida I., Kumja M., Yap C., Choon Ng 2008, , Isotherms and thermodynamics for the adsorption of n-butane on pitch based activated carbon, Int. J Heat and Mass Tran. 51, 1582-1589.

17. Witbowo N., Setyadhi L., Witbowo D., J. Setiawan, S. Ismadji 2007, Adsorption of benzene and toluene from aqueous solutions onto activated carbon and its acid and heat treated forms: Influence of surface chemistry on adsorption. J. Hazard. Mater. 146, 237-242.

18. Yuh-Shan Ho, 2006 Isotherms for the sorption of lead onto peat: comparison of linear and non-linear methods. Pol. J. Environ. Stud. 15, 81-86. 